\title{
Global Leaders in East and West: do all global leaders lead in the same way?
}

Book or Report Section

Accepted Version

Agrawal, A. and Rook, C. (2014) Global Leaders in East and West: do all global leaders lead in the same way? In: Osland, J. S., Li, M. and Wang, Y. (eds.) Advances in Global

Leadership. Advances in Global Leadership, 8. Emerald, pp. 155-179. ISBN 9781783504794 Available at http://centaur.reading.ac.uk/66835/

It is advisable to refer to the publisher's version if you intend to cite from the work. See Guidance on citing.

Publisher: Emerald

All outputs in CentAUR are protected by Intellectual Property Rights law, including copyright law. Copyright and IPR is retained by the creators or other copyright holders. Terms and conditions for use of this material are defined in the End User Agreement. 


\section{www.reading.ac.uk/centaur}

\section{CentAUR}

Central Archive at the University of Reading

Reading's research outputs online 
GLOBAL LEADERS IN EAST AND WEST -

DO ALL GLOBAL LEADERS LEAD IN THE SAME WAY?

\author{
Anupam Agrawal ${ }^{1}$ and Caroline Rook $^{2}$
}

${ }^{1}$ College of Business, University of Illinois at Urbana-Champaign, 1206 S Sixth Street, Champaign, IL 61820, USA; e-mail: anupam@illinois.edu

${ }^{2}$ Anglia Ruskin University, Lord Ashcroft International Business School, Cambridge Campus, East Road, Cambridge, CB1 1PT, UK ; e-mail: caroline.rook@anglia.ac.uk 


\begin{abstract}

\section{Research paper}

Purpose. To explore whether differences in leadership dimensions can be attributed to the leaders' cultural origins.

Design/methodology/approach. Data from 1,748 middle, and top management executives collected via the Global Executive Leadership Inventory (GELI; Kets de Vries, 2005), which measures global leadership behavior across twelve dimensions, were analyzed using multilevel modeling to derive insight into whether ratings of global leaders differ on the basis of their cultural origins.
\end{abstract}

Findings. While global leaders across the world display similar patterns of leadership behavior, there are significant differences in some leadership dimensions that can be attributed to the leaders' cultural origins.

Research Implications. While significant differences in some leadership dimensions across cultures exist, and can be attributed to the leaders' cultural antecedents, it is not clear how these differences emerge, or can be mitigated. Future research can focus on these aspects.

Keywords: global leadership, cultural leadership, GELI, 360-degree assessment 


\section{INTRODUCTION}

While it is generally accepted that there are global leadership behaviors that characterize successful leaders in a global context, discussion is on-going as to what the definition of 'global leadership' should encompass. This is due to the multidisciplinary origins of theories of the concept (Osland, 2013a) and the existence of multiple theories that highlight a wide array of global leadership competencies (Bird, 2013). Most of these can be categorized as business and organizational acumen, managing people and relationships, and managing self (Bird, 2013). The Global Executive Leadership Inventory or GELI (Kets de Vries, 2005), which integrates these competencies, has been successfully used in the coaching and development of global leaders (Kets de Vries, Florent-Treacy, Guillen, \& Korotov, 2010). We review how it measures global leadership behavior with a 360-degree feedback approach and use data collected via the GELI to analyze whether a multinational sample leads in the same way. Thus, our research question is: Do executives who have global responsibilities and who have different cultural origins deploy the same global leadership behavioral patterns?

In this research, we explore how leaders from different cultural backgrounds rate their own global leadership behavior and are perceived by people stemming from different cultures. Thus, our focus is on exploring comparative leadership as we study leaders from various cultures. We do not study 'global leadership' as our sample did not solely include leaders that lead globally across cultures. Global leadership is different from comparative leadership as it explores how executives lead across cultures rather than leading people in different cultures. In other words, global leadership competencies are those that enable to perform leadership outside one's own national and organizational culture and that enable a person to work across cultures, i.e. globally (Jokinen, 2004), thus, global leadership is characterized by a context of complexity, flow, and presence (Mendenhall, Reiche, Bird, \& 
Osland, 2012). This chapter focuses on comparative leadership: We explore differences and similarities of leadership styles of different cultures (Osland, 2013a). Our exploration and analysis also does not deal with transformational or transactional leadership (Waldman, Bass \& Yammarino, 1990). We contribute to the literature by testing comparative leadership on the dimensions as enunciated by GELI. This analysis does not tell us about the effectiveness of one leadership style over another; rather we contribute by pointing out differences due to cultures in a very wide sample of leaders and followers.

There is a rich history of comparative leadership research that provides evidence of the impact of culture on leadership. Leadership behaviors and what is seen as effective leadership varies amongst cultures. The GLOBE study is one of the most extensive comparative leadership research projects. In GLOBE 3 (Dorfman, Javidan, Hanges, Dastmalchian, \& House, 2012) it was shown that while the ideal characteristics are the same in all countries, some globally endorsed leadership styles varied in the magnitude of their endorsement across cultures: "Leaders behave in a manner consistent with the desired leadership found in that culture" (Dorfman et al., 2012, pp.. 511). The ideal of visioning, for example, is less important for Russians than for Americans (Dorfman et al., 2012). There are however universally preferred leadership behavior and characteristics such as being motivational, communicative, trustworthy (Hartog et al., 1999) or having the capacity to articulate tangible vision, values, strategies, or to be a catalyst for strategic and cultural change, to achieve results, to empower others, and to exhibit strong customer orientation (Yeung \& Ready, 1995).

Comparative leadership studies (such as GLOBE) can contribute to the field of global leadership by outlining that national leadership styles commonalities and differences emerge due to national cultures (Osland, 2013a). Complementing these studies, we analyze a large pool of data on global leadership capacities from leaders across the world to explore whether 
leaders who have followers from different cultures do in fact adapt their leadership behavior to the situation and people, and whether nationality influences the behavioral patterns of leaders.

Overall, we first explore what effective global leadership behaviors are, how global leadership behaviors can be developed, and how global leadership behavior is measured with the GELI. We then outline our methodology, and finally explain our results and their implications. Our findings are relevant for leadership development of global organizations that aim to enact effective leadership globally and nationally.

\section{What makes a Successful Global Leader?}

For several decades now leadership scholars have been attempting to outline crucial global leadership skills. A full review of empirical research on global leadership skills is beyond the scope of this chapter and has received excellent treatment in previous publications (e.g. Bird \& Osland, 2004; Jokinen, 2005; Osland, 2013b). According to Kets de Vries and Mead (1992), a number of leadership qualities are recurrent in the literature, which seem to apply to global leaders: envisioning, building relationships with others, inspiring others based on living one's values, the ability to build and maintain an organizational network, and hardiness, i.e. resilience. In general, most effective leaders simultaneously fulfill two roles: one charismatic, the other architectural (Kets de Vries, Florent-Treacy, Vrignaud, \& Korotov, 2007). Recently, Bird (2013) reviewed research spanning from 1993 to 2012 to identify commonalties in order to establish what crucial global leadership skills might be. They found 160 skills and clustered these into 15 competencies that can be grouped into the three categories of business and organizational acumen (visioning and strategic thinking, leading change, business savvy, organizational savvy, managing communities), managing people and relationships (valuing people, cross-cultural communication, interpersonal skills, teaming 
skills, empowering others), and managing self (inquisitiveness, global mindset, flexibility, character, resilience).

In this book chapter we focus on one set of empirical research that identified global leadership skills based on the behaviors of successful global leaders who participated in leadership development at one of the top international business schools. Kets de Vries and his colleagues developed a program of research that focused first on identifying aspects of global leaders, which resulted in the GELI, and second on development methods. Using empirical case studies of three global leaders who are acknowledged as being highly successful Richard Branson from Virgin, Percy Barnevik from ABB, and David Simon from British Petroleum - they identified several common leadership characteristics (Kets de Vries \& Florent-Treacy, 1999). These global leaders all had a vision that was expressed with enthusiasm and confidence. They could connect to their employees with empathy and address their concerns. They created an environment or organizational culture with shared values, open communication, commitment, and learning. And they kept the organizational structure flat.

\section{Developing the GELI}

The GELI was developed with the aim of furthering the understanding of what successful global leaders really do. Kets de Vries and colleagues studied top executives who participated in a program at INSEAD entitled "The Challenge of Leadership." Executives who attend the program can be considered as global leaders because they either work for global or transnational organizations or for organizations that focus on domestic markets but are attuned to the global context in which their competitors operate (Kets de Vries, et al., 2010). While there exist many approaches to identify global leaders (e.g. Mendenhall, Reiche, Bird, \& Osland, 2012), we use an occupation-based identification of global leaders. 
The GELI gives a clinical orientation to the exploration of leadership, by using findings from psychoanalysis, cognitive theory, developmental psychology, and family systems theory to arrive at a more complete understanding of the relations that exist between leaders and followers (Kets de Vries, 2008). In deconstructing the dynamics of leadership, it looks at the triangle of a person's mental make-up consisting of emotion, cognition, and behavior. It is important to understand a person's 'inner theatre' (Kets de Vries, 2008) or the dramas and scripts that play out from birth onwards. Understanding the inner theatre facilitates a holistic understanding of behavior and character attributes and thus helps us to understand the basis of a person's leadership style and how to change it where necessary (Kets de Vries, 2008).

Exploratory semi-structured interviews were conducted with over 300 senior executives for the development of the instrument. Each of them were asked what issues were most important to them in their day-to-day work, what kind of behaviors contributed to their effectiveness, and what issues they are facing in their personal lives. Items of the GELI were created based on these interviews and from data derived from observations of executive teams in their work settings (Kets de Vries, Vrignaud, \& Florent-Treacy, 2004).

The results revealed the underlying drivers of successful leaders (Kets de Vries, et al., 2010), which show some complementarity with universal motivational need systems (Kets de Vries \& Florent-Treacy, 2002). In general, successful leaders enact two roles. First, the charismatic role encompasses envisioning, empowering, and energizing, which helps followers find direction, inspiration, and motivation. Second, the architectural role encompasses, for example, designing and aligning. World-class executives combine these roles and focus on twelve main behaviors - the GELI leadership behavior dimensions, described in Table 1. 
Insert Table 1 about here

\section{Developing Global Leaders with a 360-degree Leadership Measurement}

Assessing the skill sets of leaders is a central part of leadership development. Therefore, the GELI is utilised in leadership development programmes, particularly in executive coaching, where it is used to help identify the operational modes of individual executives. The instrument enables the user to determine areas of leadership behavior where improvement is needed. The multi-rater process, and in particular, group coaching that involves the discussion of peer feedback from multiple perspectives in a group coaching environment where feedback is given by several other participants, triggers self-reflection and awareness of one's own leadership beliefs and enacted leadership behavior (e.g. Ward, 2010; Palevsky, 2010).

A 360-degree instrument is particularly valuable for assessing the leadership behavior of a person because many top executives are surrounded by people who tell them what they want to hear. Some leaders tend to be narcissistic: " $70 \%$ of executives believe they are in the top $25 \%$ of their profession in terms of performance" (Kets de Vries, et al., 2007: 76). Thus, it can be is difficult for executives to reflect on their leadership styles and personality characteristics in order to change their behavior, especially if they have an inflated opinion of their competence.

360-degree feedback systems give a much more accurate picture than a mere selfassessment of what executives do and how they behave. The strengths and weaknesses of their leadership behaviors can then be evaluated and developed with this information. A multiple feedback approach gives managers a more accurate view of themselves (Church \& 
Bracken, 1997; London \& Beatty, 1993; Yammarino \& Atwater, 1993, 1997; Carlson, 1998; Bland, Edwards, \& Kuhi, 1994). It minimizes the social desirability factor and sets the stage for greater acceptance of other people's views (Mohrman, Resnick-West, \& Lawler, 1989).

The 360-degree format of the GELI questionnaire allows input from all life domains, including non-work settings. This, in our opinion, helps us get a fuller picture of an individual in a world where distinctions between work and non-work have become increasingly blurred (e.g. Major \& Germano, 2006). It also helps us avoid some of the possible pitfalls associated with using 360-degree measurements in organizations such as inflated ratings or Halo error (Peiperl, 1999). The feedback from the GELI helps executives understand how they manage their public and professional selves and illustrates the level of consistency between presentations of the self. Responses also show differences in how people interact with superiors and subordinates (Kets de Vries, 2005).

\section{The Effect of Culture on Leadership}

Despite the cross-cultural nature of global leadership behaviors, some scholars argue that there are differences in how cultures perceive what effective leadership is. Cross-cultural leadership research such as the GLOBE study (e.g. House, et al. 1999; Dorfman, et al., 2012) or Hofstede (1980) have sought to predict the impact of cultural variables on organizational processes and leadership. Hofstede (1980) identified four broad dimensions of national culture based on extensive analysis of survey data conducted at IBM from 1967 to 1973 , which sampled approximately 11,600 people across 40 countries. These four dimensions are collectivism-individualism, power distance, masculinity, and uncertainty avoidance. Hofstede (1980: 25) defines culture as "the collective programming of the mind which distinguishes the members of one human group from another". He emphasizes that culture is shared among a human group, for example, a nation. This definition reflects norms and values, beliefs and 
attitudes, and mentalities (Wuthnow \& Witten, 1988), with the assumption that the implicit or informal aspects of the organization can be understood by unraveling the psychological processes that give meaning to surface manifestations of culture (Ouchi \& Wikins, 1985).

According to Hofstede (1980), values and cognitive functions are heavily influenced by national identity and therefore have an impact on behavior and cognition in organizational life. However, some scholars criticize this approach for its failure to take into consideration "how the dynamics of leadership shape and determine cultures that supposedly shape and influence leadership. (...) both leaders and followers exert considerable, sustained and often very strategically intentional influence over the contextual factors that can also be looked at as a dynamic social process rather than a static characteristic" (Guthey \& Jackson, 2011: 166). These authors further argue that while it is dangerous to ignore the importance of national culture, it is also dangerous to overstate it. For example, Denison, Kotrba, and Castano (2012) explored the utilization of 360-degree feedback leadership assessment across cultures and found that the observed differences between cultures were minimal.

Overall, our aim is to discover whether self-ratings of global leaders and ratings of their peers, subordinates, and superiors differ in a significant way depending on their culture. We use the self- and observer- ratings of leaders measured via a 360-degree feedback tool (GELI) over several years to assess whether leaders in different cultures deploy global capabilities in different patterns.

\section{METHODOLOGY}

\section{Sample}

The data were gathered from 1,748 middle, and top management executives who attended leadership development programs at INSEAD between 2001 and 2007. The sample of executives (self-raters or selves) consisted of $81 \%$ men $(n=1416)$ and $19 \%$ women $(n=$ 
332) who were on average 40.71 years old $(S D=7.76, \operatorname{Min}=24, \operatorname{Max}=72)$ and were from diverse industries in the private and public sectors such as banking, consulting, and telecommunications. The sample executives and their 13,166 observers represent 128 nationalities in the ten national clusters identified by the GLOBE study (see House, et al., 1999). These are displayed in Table 2.

Insert Table 2 about here

\section{Data}

The participants and their seven to ten observers completed the GELI survey electronically. The instrument employs a 7-point Likert scale to indicate how well the scale items describe the participant. The continuum of responses ranges from "does not describe me at all" to "describes me very well." As an example, one item on the scale reads "I establish a sense of direction in the organization." The GELI has good reliability ranging from $\alpha=.77$ to $\alpha=.91$ for the subscales (Kets de Vries et al., 2004).

\section{Analysis}

To explore our research question we used data collected from the 360-degree instrument (GELI). Analysis of data collected from a 360-degree instrument presents a multitude of challenges. The responses are from the leaders (the 'selves') and their raters. The first challenge is that the raters are related to the particular participants that they are evaluating. Therefore the dataset is a hierarchical one, where we need to control for the effects of the nesting between the raters and the selves. The second challenge is that the selves are rated by four kinds of observers: superiors, subordinates, coworkers, and other 
external/internal stakeholders such as suppliers, buyers, family, and friends. This heterogeneity presents assessment challenges for cultural research in the arena of leadership. For example, there can be differences in the cultures from which the selves and the observers come - the self may be German but a superior may be Indian, while a subordinate may be Chinese. We had to control for these effects in addition to variables such as age, sex, or the industry in which the selves and the observer raters operate.

Since raters are clustered in selves, observations for the same self are likely to be correlated because of unobserved self-level effects. To adjust for this we used multilevel or hierarchical modeling of data (Goldstein, 1995). The unobserved self-level effects were considered as fixed parameters. In order to analyze the data, we used fixed-effect estimates for the variance-component model of leadership for each of the twelve dimensions. (The Hausman test statistic was greater than the critical value of Chi-squared for all dimensions. Given this result, the preferred model is the fixed-effects model.) Thus, we have twelve different equations, one for each of the 12 leadership dimensions in GELI, and these dimensions are our dependent variables. The coefficients of all raters other than the selves were significant for most of the dimensions, indicating that a 360-degree analysis of data was called for.

We analyzed the data in two stages. In the first stage we focused on a broad categorization - we tested the twelve dimensions of leadership from the GELI for significant differences between the East and West metaclusters. We divided the countries for all selves and all observers into two metaclusters East and West, based on the categorization followed in the GLOBE studies. We coded a dummy variable selfeast for clustering between the selves - this binary variable was coded 1 if the leader (self) is from the East metacluster, and 0 otherwise. The variable selfeast was our primary independent variable. We tested whether selfeast was significant for the 12 dimensions of leadership when we controlled for age, sex, 
industry background, and respondent type (i.e., whether the respondent was self, superior, coworker, subordinate or belonged to the others category). We also added additional control variables, one each for the four types of respondents from the East metacluster (the variables were named superior_east, coworker_east, directreport_east and others_east - these controlled for the cultural effect of the rater). Table 3 (on the following pages) presents this first stage model.

In the second stage we analyzed the cultural differences at a lower level than the two metaclusters. We used the cultural clusters identified in the GLOBE project and subdivided the metaclusters as follows: West: Latin America, Latin Europe, Germanic Europe, Anglo, Nordic Europe; East: Eastern Europe, Middle East, Sub Saharan Africa, Southern Asia, Confucian Asia. We allocated observations to a cluster based on the country of the respondent in the database. While the GLOBE project was based on only 61 cultural societies, we added countries to the clusters based on the clustering of similar and neighboring countries. For example, Pakistan was added to the Southern Asia cluster, based on the fact that India was in the cluster and Pakistan has very similar cultural antecedents to India. (Before 1947, the two countries were a single entity and the subcontinent was a British colony.) Similar to the denomination in the GLOBE project, French-speaking Swiss respondents were classified under Latin Europe, whereas the other Swiss respondents were classified under Germanic Europe. In the second stage, our unit of analysis is the individual manager, and the cluster from which he/she comes from.

To add the cluster dummies to our model, we first replaced the dummy variable selfeast with a set of dummy variables indicating the cultural clusters of the participants. Subsequently, we replaced the variables others_east, superior_east, directrep_east, and coworker_east with a set of dummy variables, replacing these variables one at a time. We used hierarchical modeling, similar to the earlier analysis. All the control variables from the 
earlier analysis were retained so that we could analyze the variance due to clusters. Table 4 (on the following pages) details the matrix of coefficients for the twelve dimensions of leadership for these clusters for selves.

We also included covariates. Similar to cultural norms, leadership behavior is also influenced by the organizational and even departmental context in which the individual is working or leading (Jepson, 2009). In order to make sure that the differences could be attributed to the culture of the leaders, we controlled for the industries the leaders were working in, as well as their age and gender (Vaerenbergh \& Thomas, 2012). We report standard errors that have been adjusted for intra-self correlations, thus taking care of not only the heteroscedasticity of residuals but also ensuring that these residuals can be correlated within each self.

\section{RESULTS}

The data show that there are differences between the self and observer ratings among the East and West metaclusters in many dimensions (see Table A1). On average, observer ratings are lower than self-ratings for all dimensions for both metaclusters. Our interest is in exploring whether these differences are significant even when we control for other variables that can affect the ratings for these leadership dimensions.

In the following paragraphs, the results are outlined first for the metaclusters according to self-ratings and observer ratings (stage 1). Then the results of the more detailed analysis of the national clusters according to the self-ratings are reported (stage 2). 


\section{Stage 1: Differences between ratings of global leadership dimensions in East and}

\section{West Metaclusters.}

General Results. There are no significant industry effects on any self-rated leadership dimensions. Gender effects are significant in only five dimensions. Male leaders' self-ratings are significantly $(p<0.001)$ higher for five dimensions of leadership (Visioning, Energizing, Designing \& Aligning, Global Mindset, and Outside Orientation). Ratings for the remaining dimensions of leadership are not significantly affected by the gender.

The results are outlined in detail in Table 3, which details the coefficients of gender, age, industry, observer raters, and selves for the twelve dimensions of leadership for East and West metaclusters. The twelve dimensions of leadership are reported in columns, and the explanatory and control variables are detailed in rows.

Results for selves for East versus West. The results for differences of self-ratings between East and West are displayed in detail in Table 3. The variable selfeast is significant for four dimensions of leadership. Eastern leaders rate themselves higher $(p<0.001)$ on the dimensions of Designing \& Aligning, Outside Orientation, and Emotional Intelligence and Resilience to Stress. There are no significant differences for the other eight dimensions of leadership. Therefore, we can assert that there are significant differences between the ratings of leaders from the East and West metaclusters in these four leadership dimensions. Note that these differences exist when we control for confounding factors such as gender, ratings from self or observers, ratings from observers belonging to either the East or the West metacluster, and whether the observers are superiors, subordinates, coworkers or other stakeholders.

Results for observers for East versus West. In general, the observers (coworkers, superiors, and direct reports) rate the leaders lower in all dimensions. Higher ratings are reported in some dimensions but these effects are not significant. We expand on the significant effects related to observers belonging to the East or West metacluster below. 
Direct reports from the East. Direct reports from the East metacluster rate their leaders higher, and this effect is significant $(p<0.01)$ in eight dimensions: Visioning, Empowering, Energizing, Designing \& Aligning, Rewarding \& Feedback, Team Building, Outside Orientation, and Emotional Intelligence. The effect on leader ratings in the other four dimensions is not significant.

Superiors from the East. Superiors from the East metacluster rate the leaders lower in the Tenacity and Resilience to Stress dimensions but higher in the Life Balance dimension ( $p$ $<0.01)$. The effect on leader ratings of a cultural change from the East to the West metacluster among superiors in the other nine dimensions is not significant.

Co-Workers from the East. Co-Workers from the East metacluster gave a higher rating in four dimensions: Empowering, Designing \& Aligning, Rewarding \& Feedback, and Emotional Intelligence. The effect on leader ratings in the other eight dimensions is not significant.

Others from the East. Other stakeholders (such as a supplier) of a leader in the East metacluster gave a higher rating in the Outside Orientation dimension. The effect on leader ratings in the other eleven dimensions is not significant.

Insert Table 3 about here

\section{Stage 2: Analyzing differences in leadership behavior between national clusters}

\section{based on self-ratings.}

The results of analysis of leadership behavior for different cultural clusters are outlined in Table 4, which details the coefficients of selves for the twelve dimensions of 
leadership for the ten cultural clusters. The twelve dimensions of leadership are reported in columns, and the cultural clusters are in rows.

Our analysis shows that leadership is culturally sensitive. We saw in the stage 1 analysis that there was a significant difference in leadership ratings for leaders from the East metacluster in the Designing \& Aligning, Outside Orientation, Emotional Intelligence, and Resilience to Stress dimensions. However, these are merely group level effects, and finer analysis at a cluster level shows that other dimensions are also culturally sensitive. Indeed, there is at least one cultural cluster which accounts for significant differences (at $p<0.001$ levels) in leadership ratings among all the dimensions of leadership except Energizing. The Energizing dimension of leadership is not culturally sensitive even at a national cluster level. In the following paragraphs, we detail how leadership differs in the ten cultural clusters.

Visioning. Leaders from South-East Asia are likely to be rated higher, while a leader from a country of the Anglo-cluster is likely to be rated lower.

Empowering. Leaders from Anglo-countries are likely to be rated lower in this dimension. Leaders from East European countries are rated higher on average for Empowering.

Energizing. This is the only dimension where the coefficients are not significant for any cultural cluster. We can infer that the Energizing dimension of leadership is not significant from a cultural perspective.

Designing \& Aligning. The Western clusters of Anglo, Germanic Europe, and Latin Europe have significant negative coefficients, indicating that, on average, leaders from these countries are likely to be rated lower in this dimension. In contrast, the coefficient for the South-East Asian cluster is positive and significant.

Rewarding \& Feedback. Leaders from the Anglo-cluster have lower ratings on average, while the Middle East leaders have higher ratings on average. 
Team Building. Only leaders from the Anglo cluster have lower ratings on average. There are no other clusters that have significant ratings.

Global Mindset. While this dimension is not relevant at a metacluster level, at the cultural cluster level we see that Nordic European leaders are rated higher in this dimension on average.

Outside Orientation. This dimension is one of the four that differentiate between Eastern and Western leaders at the metacluster level. The Middle East and Southern Asia clusters have significant positive coefficients in this dimension, signifying that for these clusters outside orientation is a more manifested/practiced leadership dimension and that leaders are likely to be rated higher on this dimension. This coefficient is negative and significant for Anglo, Germanic Europe, and Latin Europe, which means that for these clusters outside orientation is a less manifested/practiced leadership dimension and that leaders are likely to be rated lower on this dimension.

Tenacity. The coefficients in this dimension are only significant for the East European cultural cluster. Further, there are no clear trends at the cluster level (the clusters in both the East and West metaclusters have positive and negative coefficients), indicating that this dimension permeates the East-West boundary.

Emotional Intelligence. The coefficients in this dimension are also significantly different between the Eastern and Western clusters. Anglo and Germanic Europe have negative coefficients, while the Middle East cluster has positive significant coefficients.

Life Balance. This dimension presents a deviation. Only the Middle East cluster results are significant; it has a significant negative coefficient, indicating that leaders from the Middle East cluster are likely to be rated lower compared to leaders from any other cluster.

Resilience to Stress. The leaders from the Western clusters of Latin Europe, Germanic Europe and Nordic Europe have lower ratings on average. The Middle East cluster has a 
significant and high positive coefficient, signifying that this dimension is culturally significant. The South-East Asian cluster also has a significant positive coefficient. Therefore we can assert that this behavior is more manifest in the managers from the Middle East \& Southern Asia clusters.

Insert Table 4 about here

\section{DISCUSSION}

We wanted to find out whether leadership styles in global executives differ between cultures by examining whether global leaders from the 'East' are perceived as having different leadership behavior patterns than their Western counterparts. The multilevel modeling analyses of self-ratings and observer ratings showed many similar patterns of global leadership behavior. However, significant differences in some leadership dimensions across cultures exist, and we can attribute these differences to the leaders' cultural antecedents.

Our analysis focused on isolating the differences among cultures in these leadership dimensions. While responses from individuals cannot provide reliable estimates about cultures, they can supply information about differences among these cultures if we have matched samples or alternatively if we control for factors such as industry, age, and gender. Controlling for these factors, as well as for the cultural antecedents and the roles of observers, we found that global leaders from the 'East' are perceived as exhibiting higher levels of leadership traits on the dimensions of Designing \& Aligning, Outside Orientation, and Emotional Intelligence, and having a higher level of Resilience to Stress. 
We also explored the leadership dimensions at the level of cultural clusters and found that some leadership dimensions are sensitive at the cultural cluster level. Leaders from South-East Asia are likely to be rated higher on the dimensions of Visioning. Leaders from a country of the Anglo-cluster are likely to be rated lower on Visioning, Empowering, Rewarding \& Feedback, and Team Building. Leaders from East European countries are likely to be rated higher on average for Empowering and Tenacity, whereas Nordic European leaders are likely to be rated higher on the Global Mindset dimension. Leaders from the Middle East are likely to be rated higher on Emotional Intelligence but lower on having a better Life Balance. Overall, we find that there are significant differences in some leadership dimensions that can be attributed to the leaders' cultural origins. Note that we control for the nationalities of the respondents when we analyze differences in leadership dimensions, and therefore our results are robust to respondents' culture.

If the GELI is designed to measure truly global capabilities, why do we find differences between cultures? To answer this, we have to ask another question: What do we mean by global? Indeed, Mendenhall et al. (2012) alert us that some existing definitions of global leadership lack rigor, precision, and similarity. Furthermore, global leadership is often conflated with comparative leadership. Global leaders need an understanding of cultural leadership styles to lead multicultural followers effectively, and global leadership encompasses skills that are necessary to lead a global company across cultural boundaries. However, when leading people from multicultural backgrounds, not all global leadership behaviors are perceived by the leaders and their observers as practiced to the same extent. In some countries certain capabilities are more practiced than others by successful leaders depending on the person or situation they are interacting with. Furthermore, perceptions of leadership are influenced by culture. The GLOBE 3 study (Dorfman, et al. 2012: 510) found that "national culture values do not directly predict CEO leadership behavior. Instead, we 
[GLOBE authors] demonstrate that national culture values are antecedent factors which influence leadership expectations." Indeed, implicit leadership theories (e.g. Lord \& Maher, 1991) propose that people evaluate leaders based on how they fit their leader prototype. Effective leadership, therefore, would be based on the leader's ability to understand different prototypes and to match their behavior to them (Gentry \& Eckert, 2012). The context in which the GELI was completed, however, may have cued the answers. The GELI is completed in preparation for INSEAD coaching programmes to which global leaders from all over the world are invited, and the coaching takes place in a multicultural environment. In anticipation of the program, the self-raters may have been less influenced by culture than the observers, who did not anticipate the multi-cultural environment but completed the GELI in their usual working environment.

The differences may also stem from cultural differences that influence cognition. What resembles leadership effectiveness is seen somewhat differently in different cultures. The early GLOBE studies looked at the attributes rather than the behaviors of leaders, so we cannot determine whether the same attributes were associated with the same behavior (Dorfman, et al., 2012). For example, integrity is a universally desirable leadership attribute, but does integrity mean the same to a Chinese person as it does to an American (Guthey \& Jackson, 2011)? The GELI looks at enacted attributes, i.e. observable behavior. However, even using behavioral items in a questionnaire may not ensure an objective description of what leaders actually do. This is because there are cultural norms regarding questionnaire completion (Bachman \& O’Malley, 1984; Harzing, Brown, Koester, \& Zhao, 2012). The Japanese, for example, show less extreme response behavior than Americans (Harzing, 2006). Cultural values not only influence questionnaire answering behavior but also what is seen by the person who receives the rating as important feedback (Denison, et al., 2010). It is likely that the values of the countries are reflected even in ratings of actual behavior due to 
the social desirability factor when completing a questionnaire. For example, if emotional intelligence is not seen as very important in one culture, then leaders might not enact that behavior as much but also might not tend to rate themselves as highly in this capacity. Beyond cultural influences, other factors are likely to have an influence on perspectives on leadership behaviour. Caligiuri and Tarique (2009) found, for example, that extraversion moderates the effect of cross-cultural leadership development on global leadership effectiveness. Particular job demands of different industry sectors or job types are also likely to influence what kind of leadership behaviors are required and therefore valued and shown by leaders.

In terms of stereotypes, it is important for global leaders not only to recognize cultural preferences of leadership styles in different nations, but also to pay attention to the individual uniqueness of people beyond their culturally determined cognitions and behaviors. Holt and Seki (2012) highlight that successful global leaders did not use generalizations or stereotypes in their global assignments. They approached other individuals with a curious and holistic perspective on the person, looking beyond their cultural identity.

For future research it would be fruitful to look more closely at why there are cultural variances in enacted global leadership behaviors and what this means when considering leadership evaluations and development in multi-cultural contexts. The GELI data does not capture the working environment of leaders, and also does not capture the leadership dynamics (or changes over time). Future work can focus on exploring if leaders from various cultures behave differently in different contexts and with different people. Indeed leadership behavior can change even when leaders come from the same culture: We do not address this with our data. One could also look at cultural differences amongst observers of the same participant. For example, when doing leadership evaluations or leadership development in a multicultural company, what would the implications be for participants valuing feedback and 
using feedback for their own development if Eastern raters rate a participant higher in some dimensions than Western raters do or vice versa?

\section{CONCLUSION}

This chapter reported on data collected via the Global Executive Leadership Inventory (GELI), which measures global leadership behavior across twelve dimensions, to derive insight into whether ratings of global leaders differ on the basis of their cultural origins. One of the contributions of this chapter is that it provides evidence that the twelve global leadership capabilities are in fact demonstrated (according to self- and observer-ratings) by effective global leaders in countries across the world. Another contribution is that global leaders apparently have to adapt their behavior to the country in which they are doing business or engaging in leadership since cultural differences are present. For example, visioning is an important leadership capability in all countries, but leaders from South-East Asian countries showed visioning behavior more than leaders from a country of the Anglocluster, which seems to indicate a greater expectation for this behavior. Indeed, the global business environment poses specific criteria for effectiveness of leaders in order to deal with the global environment characterized by complexity, change, and ambiguity. However, as also outlined by the GLOBE study, different cultures place different values on certain leadership behaviors and styles. Therefore it seems that cultural sensitivity and a holistic approach to individuals are necessary qualities, in addition to enacting the twelve global leadership skills, when a global leader has followers from different countries. 


\section{ACKNOWLEDGEMENTS}

Caroline Rook conducted this research during her Research Fellowship at INSEAD, Europe Campus and acknowledges the INSEAD Dutch Alumni for funding her research. Anupam Agrawal would like to thank the INSEAD Global Leadership Center for supporting this research and Pierre Vrignaud for advice on statistical modeling. Both authors would like to thank Manfred Kets de Vries, Elizabeth Florent-Treacy, Alicia Cheak-Baillargeon, Parisa Gilani, and Joyce Osland for their comments on drafts of this chapter. 


\section{APPENDIX}

TABLE A1

Means and standard deviations of ratings by selves and observers for the twelve dimensions of leadership for the East and West metaclusters

\begin{tabular}{|c|c|c|c|c|c|c|}
\hline & \multicolumn{2}{|c|}{ Total Data } & \multicolumn{2}{|c|}{ East } & \multicolumn{2}{|c|}{ West } \\
\hline & Self & Observers & Self & Observers & Self & Observers \\
\hline Visioning & $\begin{array}{l}45.82 \\
(4.64)\end{array}$ & $\begin{array}{c}43.84 \\
(6.71)\end{array}$ & $\begin{array}{l}46.36 \\
(5.01)\end{array}$ & $\begin{array}{l}44.39 \\
(7.04)\end{array}$ & $\begin{array}{l}45.69 \\
(4.53)\end{array}$ & $\begin{array}{c}43.70 \\
(6.62)\end{array}$ \\
\hline Empowering & $\begin{array}{l}44.49 \\
(5.19)\end{array}$ & $\begin{array}{l}41.65 \\
(7.4)\end{array}$ & $\begin{array}{l}44.82 \\
(5.60)\end{array}$ & $\begin{array}{l}42.35 \\
(7.57)\end{array}$ & $\begin{array}{l}44.41 \\
(5.08)\end{array}$ & $\begin{array}{l}41.48 \\
(7.35)\end{array}$ \\
\hline Energizing & $\begin{array}{l}45.23 \\
(5.11)\end{array}$ & $\begin{array}{l}44.12 \\
(7.18)\end{array}$ & $\begin{array}{l}45.79 \\
(5.79)\end{array}$ & $\begin{array}{c}44.58 \\
(7.62)\end{array}$ & $\begin{array}{l}45.09 \\
(4.91)\end{array}$ & $\begin{array}{l}44.01 \\
(7.05)\end{array}$ \\
\hline $\begin{array}{l}\text { Designing and } \\
\text { aligning }\end{array}$ & $\begin{array}{l}36.77 \\
(5.78)\end{array}$ & $\begin{array}{l}36.76 \\
(6.51)\end{array}$ & $\begin{array}{l}38.31 \\
(5.71)\end{array}$ & $\begin{array}{l}37.66 \\
(6.77)\end{array}$ & $\begin{array}{l}36.39 \\
(5.74)\end{array}$ & $\begin{array}{l}36.52 \\
(6.52)\end{array}$ \\
\hline $\begin{array}{l}\text { Rewarding and } \\
\text { feedback }\end{array}$ & $\begin{array}{l}43.54 \\
(5.78)\end{array}$ & $\begin{array}{l}41.35 \\
(8.03)\end{array}$ & $\begin{array}{l}44.79 \\
(6.09)\end{array}$ & $\begin{array}{l}42.39 \\
(8.3)\end{array}$ & $\begin{array}{l}43.23 \\
(5.66)\end{array}$ & $\begin{array}{l}41.08 \\
(7.94)\end{array}$ \\
\hline Team building & $\begin{array}{l}60.52 \\
(7.13)\end{array}$ & $\begin{array}{l}57.34 \\
(10.19)\end{array}$ & $\begin{array}{l}61.94 \\
(7.42)\end{array}$ & $\begin{array}{l}58.65 \\
(10.66)\end{array}$ & $\begin{array}{l}60.17 \\
(7.01)\end{array}$ & $\begin{array}{l}57.01 \\
(10.03)\end{array}$ \\
\hline Global mindset & $\begin{array}{l}44.13 \\
(6.93)\end{array}$ & $\begin{array}{l}43.50 \\
(7.54)\end{array}$ & $\begin{array}{l}43.90 \\
(6.86)\end{array}$ & $\begin{array}{l}43.44 \\
(7.63)\end{array}$ & $\begin{array}{l}44.19 \\
(6.95)\end{array}$ & $\begin{array}{l}43.49 \\
(7.52)\end{array}$ \\
\hline $\begin{array}{l}\text { Outside } \\
\text { orientation }\end{array}$ & $\begin{array}{l}27.48 \\
(3.97)\end{array}$ & $\begin{array}{l}27.56 \\
(4.51)\end{array}$ & $\begin{array}{l}28.35 \\
(4.19)\end{array}$ & $\begin{array}{l}27.87 \\
(4.66)\end{array}$ & $\begin{array}{l}27.26 \\
(3.88)\end{array}$ & $\begin{array}{l}27.49 \\
(4.47)\end{array}$ \\
\hline Tenacity & $\begin{array}{l}29.47 \\
(3.41)\end{array}$ & $\begin{array}{l}28.90 \\
(4.30)\end{array}$ & $\begin{array}{l}29.06 \\
(3.67)\end{array}$ & $\begin{array}{r}28.29 \\
(4.6)\end{array}$ & $\begin{array}{l}29.57 \\
(3.33)\end{array}$ & $\begin{array}{l}29.06 \\
(4.21)\end{array}$ \\
\hline $\begin{array}{l}\text { Emotional } \\
\text { intelligence }\end{array}$ & $\begin{array}{l}64.69 \\
(8.58)\end{array}$ & $\begin{array}{l}62.13 \\
(11.87)\end{array}$ & $\begin{array}{l}66.70 \\
(8.9)\end{array}$ & $\begin{array}{l}63.77 \\
(11.95)\end{array}$ & $\begin{array}{l}64.19 \\
(8.4)\end{array}$ & $\begin{array}{l}61.69 \\
(11.81)\end{array}$ \\
\hline Life balance & $\begin{array}{l}49.29 \\
(7.61)\end{array}$ & $\begin{array}{l}55.59 \\
(24.55)\end{array}$ & $\begin{array}{l}48.90 \\
(8.02)\end{array}$ & $\begin{array}{l}20.50 \\
(25.03)\end{array}$ & $\begin{array}{l}49.39 \\
(7.5)\end{array}$ & $\begin{array}{l}17.65 \\
(24.42)\end{array}$ \\
\hline Resilience to stress & $\begin{array}{l}33.40 \\
(10.9)\end{array}$ & $\begin{array}{l}38.86 \\
(23.91)\end{array}$ & $\begin{array}{l}37.38 \\
(11.64)\end{array}$ & $\begin{array}{l}60.7 \\
(23.37)\end{array}$ & $\begin{array}{l}32.40 \\
(10.48)\end{array}$ & $\begin{array}{l}60.55 \\
(24.04)\end{array}$ \\
\hline
\end{tabular}

Notes: $\mathrm{N}=14914$, Standard Deviations are in parentheses. 


\section{REFERENCES}

Bachman, J. G., \& O'Malley, P. M. (1984). Yea-saying, nay-saying, and going to extremes: Black-white differences in response styles. Public Opinion Quarterly, 48(2), 491509. doi: $10.1086 / 268845$

Bird, A. (2013). Mapping the content domain of global leadership competencies. In M. E. Mendenhall, J. S. Osland, A. Bird, G. R. Oddou, M. L. Maznevski, M. J. Stevens \& G. K. Stahl (Eds.), Global leadership. Research, practice, and development: 2nd ed., 80-96. London: Routledge.

Bird, A. \& Osland, J. S. (2004). Gobal competencies: An introduction. In H. Lane, M.

Maznevski, M. Mendenhall \& J. McNett (Eds.) Handbook of global management, 5780. Oxford: Blackwell.

Bland, C., Edwards, M., \& Kuhi, L. (1994) Academic administrator evaluation through colleague feedback. CUPA Journal, 45(1), 19-31. Retrieved from: http://www.eric.ed.gov/ERICWebPortal/search/detailmini.jsp?_nfpb=true\&_\&ERICE xtSearch_SearchValue_0=EJ483622\&ERICExtSearch_SearchType_0=no\&accno=EJ 483622

Caligiuri, P. \& Tarique, I. (2009). Predicting effectiveness in global leadership activities. Journal of World Business, 44, 336-346. doi: 10.1016/j.wb.2008.11.005

Carlson, M. S. (1998). 360-degree feedback: the power of multiple perspectives. Popular Government, 63(2), 38-49. Retrieved from: http://sogpubs.unc.edu//electronicversions/pg/carlson.pdf?

Church, A., \& Bracken, D. (1997), Advancing the state of the art of 360-degree feedback: Guest editors comments on the research and practice of multirater assessment methods. Group and Organization Management, 22,149-161. doi: $10.1177 / 1059601197222002$ 
Den Hartog, D. N., House, R. J. Hanges, P. J., Ruiz-Qunitanilla, S. A., Dorfman, P. W. (1999). Culture specific and cross-culturally generalizable implicit leadership theories: Are the attributes of charismatic/transformational leadership universally endorsed? Leadership Quarterly, 10(20), 219-256. Retrieved from http://web.ebscohost.com/ehost/detail?vid=3\&sid=d6e77629-2f68-4f46-accc8fbee3ce6e10\%40sessionmgr112\&hid=119\&bdata=JnNpdGU9ZWhvc3QtbG12ZQ\% $3 \mathrm{~d} \% 3 \mathrm{~d} \# \mathrm{db}=\mathrm{bth} \& \mathrm{AN}=2406537$

Denison, D. R., Kotrba, L. M., \& Castaño, N. (2012). A cross-cultural perspective on leadership assessment: Comparing 360-degree feedback results from around the world. In W. H. Mobley, Y. Wang \& M. Li (Eds.), Advances in global leadership: Volume 7, 205-228. Bingley: Emerald.

Dorfman, P., Javidan, M., Hanges, P., Dastmalchian, A., \& House, R. (2012). GLOBE: A twenty year journey into the intriguing world of culture and leadership. Journal of World Business, 47(4), 504-518. doi: 10.1016/j.jwb.2012.01.004

Gentry, W. A. \& Eckert, R. H. (2012). Integrating implicit leadership theories and fit into the development of global leaders: A 360-degree approach. Industrial and Organizational Psychology, 5(2), 224-227. doi:10.1111/j.1754-9434.2012.01434.x

Goldstein, H. (1995). Multilevel Statistical Models. London: Edward Arnold.

Guthey, E., \& Jackson, B. (2011). Cross-cultural leadership revisited. In A. Bryman, D.

Collinson, K. Grint, B. Jackson \& M. Uhl-Bien (Eds.), The sage handbook of leadership: 165-178. London: Sage.

Harzing, A. (2006). Response styles in cross-national survey research: A 26-country study. International Journal of Cross Cultural Management, 6(2), 123-141. doi: $10.1177 / 1470595806066332$ 
Harzing, A., Brown, M., Köster, K., \& Zhao, S. (2012). Response style differences in crossnational research. Management International Review (MIR), 52(3), 341-363. doi: $10.1007 / \mathrm{s} 11575-011-0111-2$

Hofstede, G. (1980). Culture's consequences: International differences in work-related values. Beverly Hills, CA: Sage.

Holt, K., \& Seki, K. (2012). Global leadership: A developmental shift for everyone. Industrial and Organizational Psychology, 5(2), 196-215. doi: 10.1111/j.17549434.2012.01431.x

House, R. J., Hanges, P. J., Ruiz-Quintanilla, S. A., Dorfman, P. W., Falkus, S. A., \& Ashkanasy, N. M. (1999). Cultural influences on leadership and organizations: Project Globe. In W. H. Mobley, M. J. Gessner \& V. Arnold (Ed.), Advances in Global Leadership: Volume 2, 171-233. Bingley: Emerald.

Jaques, E. (1989). Requisite Organization. London: Gower Publishing.

Jepson, D. (2009). Studying leadership at cross-country level. A critical analysis. Leadership, 5(1), 61-80. doi: 10.1177/1742715008098310

Jokinen, T. (2005). Global leadership competencies: a review and discussion. Journal of European Industrial Training, 29 (3), 199-216. doi: 10.118/03090590510591085

Kets de Vries, M. F. R. (2005). Global Executive Leadership Inventory: Participant Workbook. San Francisco, CA: Pfeiffer.

Kets de Vries, M. F. R. (2005). Leadership group coaching in action: The zen of creating high performance teams. Academy of Management Executive, 19(1), 61-76. doi: 10.5465/AME.2005.15841953 
Kets de Vries, M. F. R. (2008). Leadership coaching and organizational transformation:

Effectiveness in a world of paradoxes. INSEAD Working Paper, 2008/71/EFE.

Retrieved from: http://web.ebscohost.com/ehost/pdfviewer/pdfviewer?sid=bdea5f91da78-436c-a808-59f009150279\%40sessionmgr112\&vid=7\&hid=127

Kets de Vries, M. F. R., \& Florent-Treacy, E. (2002). Global leadership from A to Z:

Creating high commitment organizations. Organizational Dynamics, 30(4), 295-309. doi: 10.1016/S0090-2616(02)00067-0

Kets de Vries, M. F. R., \& Mead, C. (1992). The development of the global leader within the multinational corporation. In V. Pucik, N. M. Tichy \& C. K. Barnett (Eds.), Globalizing management: creating and leading the competitive organization: 187205. New York: Wiley.

Kets de Vries, M. F. R., Florent-Treacy, E., Vrignaud, P., \& Korotov, K. (2007). Goodbye, sweet narcissus: Using 360 feedback for self-reflection. In Kets de Vries, M. F. R., Korotov, K., \& Florent-Treacy, E. (Eds.), Coach and couch. The psychology of making better leaders: 76-106. Basingstoke: Palgrave Macmillan.

Kets de Vries, M. F. R., Vrignaud, P., \& Florent-Treacy, E. (2004). The global leadership life inventory: Development and psychometric properties of a 360-degree feedback instrument. International Journal of Human Resource Management, 15(3), 475-492. doi: $10.1080 / 0958519042000181214$

Kets de Vries, M. F. R., Florent-Treacy, E., Guillen, L., \& Korotov, K. (2010). The proof is in the pudding: An integrative psychodynamic approach to evaluating a leadership development program. In Kets de Vries, M F. R., E. Florent-Treacy, L. Guillen \& K. Korotov (Eds.), The coaching kaleidoscope. Insights from the inside: 3-19.

Basingstoke: Palgrave Macmillan. 
London, M., \& Beatty, R. W. (1993). 360-degree feedback as a competitive advantage. Human Resource Management, 39, 353-372. doi: 10.1002/hrm.3930320211

Major, D. A. \& Germano, L. M. (2006). The changing nature of work and its impact on the work-home interface. In F. Jones, R. J. Burke \& M. Westman (Eds.), Work-life balance: A psychological perspective: 13-38. New York: Psychology Press.

Mendenhall, M. E., Reiche B. S., Bird, A., \& Osland, J. (2012). Defining the "global” in global leadership. Journal of World Business, 47, 493-503. doi: 10.1016/j.jwb.2012.01.003

Mohrman, A., Resnik-West, S., \& Lawler, E. (1989). Designing performance appraisal systems. San Francisco, CA: Jossey-Bass.

Ouchi, W. G. \& Wilkins, A. L. (1985). Organizational culture. Annual Review of Sociology, 11, 457-483. Retrieved: http://rds.epiucsf.org/ticr/syllabus/courses/68/2010/04/15/ Lecture/readings/Ouchi\%20et\%20al\%201985\%20Organizational\%20Culture.pdf

Oddou, G. R., \& Mendenhall, M. E. (2013). Global leadership development. In M. E. Mendenhall, J. S. Osland, A. Bird, G. R. Oddou, M. L. Maznevski, M. J. Stevens \& G. K. Stahl (Eds.), Global leadership. Research, practice, and development: 2nd ed., 215-239. London: Routledge.

Osland, J. S. (2013a). The multidisciplinary roots of global leadership. In M. E. Mendenhall, J. S. Osland, A. Bird, G. R. Oddou, M. L. Maznevski, M. J. Stevens \& G. K. Stahl (Eds.), Global leadership. research, practice, and development: 2nd ed., 21-39. London: Routledge.

Osland, J. S. (2013b). An overview of the global leadership literature. In M. E. Mendenhall, J. S. Osland, A. Bird, G. R. Oddou, M. L. Maznevski, M. J. Stevens \& G. K. Stahl (Eds.), Global leadership. research, practice, and development: 2nd ed., 40-79. London: Routledge. 
Palevsky, M. (2010). 360-degree group coaching from the inside out. In Kets de Vries, M. F. R., E. Florent-Treacy, L. Guillen \& K. Korotov (Eds.), The coaching kaleidoscope. Insights from the inside: 102-117. Basingstoke: Palgrave MacMillan.

Peiperl, M. (1999). Conditions for the success of peer evaluation. The International Journal of Human Resource Management, 10 (3), 429-458. doi: 10.1080/095851999340413

Tichy, N. M. (1997). The Leadership Engine. New York: Harper Collins.

Ulrich, D., Zenger, J., \& Smallwood, N. (1999). Results-based leadership. Boston: Harvard Business School Press.

Ulrich, D. (2007). Leadership brand: Developing customer-focused leaders to drive performance and build lasting value. Boston: Harvard Business School Press.

Van Vaerenbergh, Y., \& Thomas, T. D. (2012). Response styles in survey research: A literature review of antecedents, consequences, and remedies. International Journal of Public Opinion Research, published online June 19, 2012. doi: 10.1093/ijpor/eds021

Ward, G. (2010). Something from nothing: The use of transitional space and how group coaching changes people. In Kets de Vries, M. F. R., E. Florent-Treacy, L. Guillen \& K. Korotov (Eds.), The coaching kaleidoscope. Insights from the inside: 71-85. Basingstoke: Palgrave MacMillan.

Waldman, D. A., Bernard M. Bass, B.M., \& Yammarino F.J. (1990). Adding to contingentreward behavior the augmenting effect of charismatic leadership. Group \& Organization Management, 15(4), 381-394. doi: 10.1177/105960119001500404

Wuthnow, R. \& Witten, M. (1988). New directions in the study of culture. Annual Review of Sociology, 14, 49-67.

Yammarino, F. \& Atwater, L.E. (1993). Understanding self-perception accuracy: implications for human resource management. Human Resource Management, 32, 2331-2347. doi: 10.1002/hrm.3930320204 
Yammarino, F. \& Atwater, L.E. (1997). Do managers see themselves as others see them? Organizational Dynamics, 25(4), 35-44. doi: 10.1016/S0090-2616(97)90035-8 


\section{TABLES}

\section{TABLE 1}

GELI leadership behavior dimensions

(adapted from Kets de Vries, Florent-Treacy, Vrignaud, \& Korotov, 2007, pp. 83-84)

\begin{tabular}{l}
\hline Dimension \\
\hline Visioning \\
Empowering \\
Energizing \\
Designing and Aligning
\end{tabular}

Rewarding and Feedback

Team Building

Outside Orientation

Global Mindset

Tenacity

Emotional Intelligence

Life Balance

Resilience to Stress

\section{Description}

Articulating a compelling vision, mission, and strategy with a multi-country, multi-environment, multi-function, and genderequality perspective that connects employees, shareholders, suppliers, and customers on a global scale.

Giving workers at all levels voice by empowering them through the sharing of information and the delegation of decisions to the people most competent to execute them.

Motivating employees to actualize the organization's specific vision of the future.

Creating the proper organizational design and control systems to make the guiding vision a reality and using those systems to align the behavior of employees with the organization's values and goals.

Setting up the appropriate reward structures and giving constructive feedback to encourage the kind of behavior that is expected from employees.

Creating team players and focusing on team effectiveness by instilling a cooperative atmosphere, building collaborative interaction, and encouraging constructive conflict.

Making employees aware of their outside constituencies, emphasizing particularly the need to respond to the requirements of customers, suppliers, shareholders, and other interest groups, such as local communities affected by the organization.

Inculcating a global mentality in the ranks; that is, instilling values that act as a sort of glue between the regional and/or national cultures represented in the organization

Encouraging tenacity and courage in employees by setting a personal example in following through on reasonable risks.

Fostering trust in the organization by creating, primarily through example, an emotionally intelligent workforce whose members know themselves and know how to deal with others with respect and understanding.

Articulating and modeling the importance of life balance for the long-term welfare of employees.

Paying attention to work, career, life and health stress issues, and balancing appropriately the various kinds of pressures that life brings. 
TABLE 2

Nationalities of participants (self-raters and observers; $N=14,914$ )

\begin{tabular}{llll}
\hline National cluster & $N$ & Self & Observers \\
\hline Anglo & 3728 & 436 & 3292 \\
ConfucianAsia & 956 & 109 & 847 \\
EasternEurope & 424 & 53 & 371 \\
GermanicEurope & 3086 & 353 & 2733 \\
LatinAmerica & 505 & 60 & 445 \\
LatinEurope & 2,918 & 348 & 2570 \\
MiddleEast & 733 & 93 & 640 \\
NordicEurope & 1,778 & 200 & 1578 \\
SouthernAsia & 712 & 86 & 626 \\
SubSaharanAfrica & 74 & 10 & 64 \\
\hline
\end{tabular}

